\title{
SABERES, [RE] CONSTRUÇÃO DE IDENTIDADES E CONTRADIÇÃO TRABALHO-CAPITAL EM COMUNIDADE QUILOMBOLA ${ }^{1}$
}

\author{
Ellen R. S. Miranda ${ }^{2}$ \\ Doriedson S. Rodrigues ${ }^{3}$
}

\begin{abstract}
Resumo
O artigo apresenta resultados de pesquisa sobre a [re]construção de identidades na contradição trabalhocapital, no contexto da Comunidade Quilombola Tambaí-Açu - Mocajuba/PA, Amazônia. Trata-se de investigação qualitativa, pautada no materialismo histórico-dialético. Conclui-se que o trabalho na comunidade é permeado por interesses antagônicos, dado a coexistência com modo de produção capitalista, configurado no monocultivo intensivo da pimenta-do-reino, e a negação a esta lógica, ao [re]criarem saberes do trabalho que compõem os mutirões quilombolas.
\end{abstract}

Palavras-chave: Trabalho-Educação; Capital; Identidades; Quilombolas; Saberes.

\section{CONOCIMIENTO, [RE] CONSTRUCCIÓN DE IDENTIDADES Y CONTRADICIÓN DEL TRABAJO- CAPITAL EN COMUNIDAD PALENQUE}

\section{Resumen}

El artículo presenta resultados de una investigación sobre la [re] construcción de identidades, en la contradicción del capital de trabajo, en el contexto de la Comunidad Quilombola Tambaí-Açu - Mocajuba / PA, Amazon. Es una investigación cualitativa, basada en el materialismo histórico-dialéctico. Se concluye que el trabajo en la comunidad está impregnado de intereses antagónicos, dada la convivencia con el modo de producción capitalista, configurado en el monocultivo intensivo de pimienta negra, y la negación de esta lógica, al [re] crear conocimiento del trabajo que compone esfuerzos colectivos de quilombola.

Palabras clave: Trabajo-Educación; Capital; Identidades; Quilombolas; Conocimiento

\section{KNOWLEDGE, IDENTITY [RE] CONSTRUCTION AND LABOR-CAPITAL CONTRADITION IN A QUILOMBOLA COMMUNITY}

\begin{abstract}
The article presents results of a master's research, on the [re] construction of identities, in the labour-capital contradiction, in the context of the Quilombola Tambaí-Açu Community - Mocajuba / PA, Amazon. It is a qualitative investigation, based on historical-dialectical materialism. It is concluded that the work in the community is permeated by antagonistic interests, given the coexistence with capitalist production mode, configured in the intensive monoculture of black pepper, and the denial of this logic, by [re] creating knowledge of the labour that compose quilombola collective efforts.
\end{abstract}

Keywords: Labour-Education; Capital; Identities; Quilombolas; Knowledge

\footnotetext{
${ }^{1}$ Artigo recebido em 29/10/2019. Primeira avaliação em 18/02/2020. Segunda avaliação: 06/03/2020. Aprovado em 22/04/2020. Publicado em 22/05/2020. DOI: https://doi.org/10.22409/tn.v18i36.38358 ${ }^{2}$ Professora da Educação Básica. Mestra em Educação e Cultura - Programa de Pós-Graduação em Educação e Cultura pela Universidade Federal do Pará (PPGEDUC/UFPA/CUNTINS) - Brasil. Doutoranda em Educação - Programa de Pós-Graduação em Educação na Amazônia (PGEDA 2020). Membro do Grupo de Estudos e Pesquisas sobre Trabalho e Educação (GEPTE/UFPA) - Brasil. E-mail:ellenrodrigues.slp@gmail.com ORCID: 0000-0002-2030-463X.

3 Doutor em Educação. Docente da Universidade Federal do Pará, Campus Universitário do Tocantins/Cametá - Pará, Brasil. .Membro do Grupo de Estudos e Pesquisas sobre Trabalho e Educação (GEPTE/UFPA). Membro do Grupo de Pesquisa História, Educação e Linguagem na Região Amazônica (GPHELRA/UFPA). E-mail:doriedson@ufpa.br ORCID: 0000-0002-5120-2484.
} 


\section{Introdução}

Neste artigo, problematizamos processos de luta e resistência de populações tradicionais do Baixo Tocantins, Estado do Pará, Amazônia, frente às ações do Capital na Região, em que mediações são produzidas, em forma de um conjunto de saberes, para darem conta de suas identidades e resistências, a ele se opondo, num processo de luta de classe. ${ }^{4}$ Para tanto, salientamos que no contexto sócio-político-cultural e econômico da Comunidade Quilombola Tambaí-Açu, município de Mocajuba, Estado do Pará, onde desenvolvemos a presente investigação, o Capital tem se manifestado pela introdução do monocultivo intensivo da pimenta-do-reino ${ }^{5}$, a partir da década de 1970, a fim de dar conta dos interesses do mercado internacional, caracterizando-se como trabalho repetitivo, individualizado, parcelado e, portanto, desumanizante.

No trabalho dos pimentais houve adesão de alguns quilombolas. Contraditoriamente, entretanto, analisamos que vêm ocorrendo resistências que se engendram como negação a este tipo de trabalho, o que se manifesta no processo cotidiano de [re]construção de saberes do trabalho colaborativo, festivo, criativo, humanizante, materializado nos mutirões quilombolas, que também consubstanciam elementos de identidade dessa comunidade.

Trata-se de investigação numa abordagem qualitativa, a partir do materialismo histórico-dialético, considerando, a partir de Araújo (2007), que os fenômenos sociais correspondem a dimensões tanto quantitativas como qualitativas, constituindo-se também culturais, de acordo com Thompson (2001), não seguindo os fenômenos econômicos à distância, pois são partes da mesma rede de relações consideradas como totalidade social, unidade do diverso (MARX, 2008). Em termos de procedimentos metodológicos, realizamos levantamento documental, observações e

\footnotetext{
${ }^{4}$ Trata-se de resultados de investigação empreendida de 2017 a 2019 no Mestrado em Educação e Cultura da Universidade Federal do Pará, Campus Universitário do Tocantins/Cametá, focando no debate sobre saberes, identidade e resistência em comunidade quilombola do nordeste do Estado do Pará. Uma primeira versão deste trabalho foi apresentada no contexto da $39^{\mathrm{a}}$ Reunião Nacional da ANPED - Associação Nacional de Pós-Graduação e Pesquisa em Educação, GT: 9 - Trabalho e Educação, realizada de 20 a 24 de outubro de 2019, na Universidade Federal Fluminense (UFF). Aqui, trata-se de versão revista e ampliada.

${ }^{5}$ Denominada cientificamente de (Piper nigrum L.), a pimenta do reino é classificada como commodity, ou seja, "[...] produtos que são produzidos para serem transacionados unicamente no mercado [...] e está associado a um tipo de organização da produção que representou historicamente a integração das economias e sociedades periféricas à divisão do trabalho no sistema capitalista internacional" (CALDART, et. al, 2012, p. 136).
} 
anotações de campo junto à comunidade, além de entrevistas semiestruturadas ${ }^{6} \mathrm{com}$ três mulheres e quatro homens, focando em tópicos sobre o trabalho nos pimentais e nos mutirões quilombolas, de modo a analisar as relações de contradição entre capital e trabalho.

Os dados das entrevistas foram tratados, em termos de significância, pela análise do conteúdo (BARDIN, 1977), numa perspectiva dialética, de modo a responder aos seguintes questionamentos: a) Como a comunidade quilombola foi impactada com a centralidade do trabalho na lógica do mercado? b) De que forma a comunidade quilombola [re]constrói suas identidades frente às tentativas de homogeneização operadas pelo capital?

O texto compõe-se de duas seções. Na primeira, apresentamos elementos sócio-históricos sobre formações dos quilombos no Pará e as transformações operadas pela introdução do monocultivo intensivo da pimenta-do-reino, a partir da década de 1970, no contexto da Comunidade Quilombola Tambaí-Açu, Mocajuba/Pará. Na segunda, articulamos dados empíricos às questões teóricas sobre formas e determinações constitutivas do capitalismo, que tentam homogeneizar materialidades, tanto objetivas quanto subjetivas, por meio de monocultivos intensivos que impactam povos de comunidades tradicionais, a fim de aniquilar processos de resistências que destoam do seu receituário, ao [re]construírem identidades coletivas, tais como a produção da vida por meio de mutirões quilombolas. Por fim, apresentamos as considerações finais.

\section{Relações de trabalho em comunidades quilombolas e ações do capital na}

\section{Amazônia paraense: entre saberes e modos de vida}

Pesquisas realizadas no Pará, a exemplo de Salles (1988), Gomes (1996; 2006; 2015), Funes (2012) e Pinto (2001; 2004; 2007) têm apontado as comunidades quilombolas como territórios ${ }^{7}$ constituídos por processos históricos de resistência ao estado opressor, opondo-se ao cárcere no período escravista, por meio de fugas e

\footnotetext{
${ }^{6}$ Para a realização das entrevistas, consideramos as orientações em Triviños (1987). A pesquisa em sua totalidade contou com nove trabalhadores/as, sendo aqui considerados dados de fala de somente 03 mulheres e 04 homens.

${ }^{7}$ Neste trabalho, entendemos território, de acordo com Nosella (2011, p. 7), como não sendo "[...] um espaço abstrato do planeta", mas como uma dimensão sócio-histórica-cultural-política e econômica sobre a realidade, a partir de mediações do trabalho, que confere concretude à história humana, materializada em experiências e saberes coletivos sobre modos de produzir e organizar a vida.
} 
formação de quilombos entre os séculos XVIII e XIX na Amazônia, a partir do que muitas resultaram.

Salles (1988) e Gomes (1996; 2006; 2012), por exemplo, salientam que, em decorrência da exploração e violência a que foram submetidos, muitas negras e negros fugiram desse estado opressivo e formaram quilombos, de onde se conclui, com base em Gomes e Reis (2012, p. 9), que "onde houve escravidão houve resistência. E de vários tipos", sendo a fuga e formação de grupos de fugidos a mais típica das resistências, de acordo ainda com Gomes e Reis (2012), com o que também concorda Funes (2012, p. 535), para o qual a "[...] resistência negra é marcada pela constituição de um espaço social alternativo ao mundo do senhor, onde ser livre foi a experiência maior". E a resistência desses quilombos, conforme Pinto (2001; 2004; 2007), tem-se dado pela organização e afirmação cultural configurada em rituais, danças, ritmos e cantorias, mantendo-se em comunidades quilombolas até os dias atuais.

O fato, pois, com base nesses autores e autoras, é que a constituição dos quilombos, com sua organização e firmação cultural, é indicador de resistência e luta no contexto do escravismo na Amazônia, "[...] onde ser livre foi a experiência maior", conforme Funes (2012, p. 535). Todavia, é possível tratarmos de resistência atualmente em comunidades quilombolas da Amazônia, considerando as relações de trabalho nela realizadas em oposição aos interesses do capital, como o que abordamos nesta investigação, a partir do mundo do trabalho em pimentais e o mundo do trabalho em mutirões.

Nesse sentido, a partir de uma comunidade tradicional quilombola da Amazônia, avançamos para o entendimento de processos de resistência e de (re)construção das identidades, como saberes, considerando as mediações e contradições entre Trabalho e Capital, no contexto do trabalho estranhado (próprio do modo de produção capitalista), operado pelo monocultivo intensivo da pimenta-doreino, implantado na região nordeste paraense, especificamente no município de Mocajuba (PA), desde a década de 1970, perdurando até o presente, e que se contrapõe ao trabalho dos mutirões organizados na Comunidade Tambaí-Açu.

Quanto ao trabalho estranhado a partir do monocultivo da pimenta-do-reino, há de se considerar, inicialmente, o contexto histórico de sua implantação no Estado do Pará. Com efeito, os primeiros imigrantes japoneses, responsáveis pela introdução 
dessa monocultura, desembarcaram em Belém do Pará entre os anos de 1929 a 1937, objetivando uma produção em larga escala, em forma de monocultivo intensivo, voltado a suprir as necessidades do mercado mundial (FLOHRSCHÜTZ e HOMMA, 1983), configurando-se uma presentificação maciça do modo de produção capitalista na região, dada a sua racionalidade, conforme Marx (2013), voltada para a expropriação da força do trabalho em prol da acumulação, concentração e centralização da riqueza e propriedade.

Nessa perspectiva, a pimenta-do-reino, configurada como produção de grandes produtores, com grandes incentivos econômicos oriundos do Estado brasileiro através de projetos a partir da SUDAM $^{8}$ e PROTERRA ${ }^{9}$, no contexto do regime militar, atraiu diversos empreendedores capitalistas para o Estado do Pará, transformando a dinâmica de produção agrícola da Amazônia, ao suplantar, muitas vezes, modos de existência pautados na agricultura consorciada, diversificada e familiar, a exemplo do vivido em Tambaí-Açu. Neste contexto, o monocultivo intensivo da pimenta-do-reino se expandiu no Estado paraense (FLOHRSCHÜTZ e HOMMA, 1983).

Por outro lado, além dos incentivos de governo, através de consórcios com Bancos ${ }^{10}$, a produção do monocultivo intensivo da pimenta-do-reino na região nordeste paraense, município de Mocajuba, Comunidade Quilombola Tambaí-Açu, foi favorecida por fatores climáticos e pela possibilidade de extensão das áreas de plantio, além do baixo custo da força de trabalho das famílias quilombolas. Para os capitalistas, eram essas condições importantes, posto que significavam mais lucratividade em relação a outros territórios exportadores, como Vietnã, onde, embora também houvesse mão-de-obra de baixo custo para atender aos interesses do mercado mundial da pimenta-do-reino, o clima e o uso de áreas de plantio não favoreciam tanto quanto a Amazônia (FILGUEIRAS, et. al., 2010).

A presença da pimenta-do-reino no Pará, após sua introdução, enfrentou ataques por fungos, como o Fusarium solani f. piperis e Phytophthora palmivora ${ }^{11}$, que impactavam negativamente a intensificação da produção, conduzindo os japoneses

\footnotetext{
${ }^{8}$ Superintendência de Desenvolvimento da Amazônia.

${ }^{9}$ Programa de Incentivo Agrícola, desenvolvido no período militar no Brasil (1964-1984).

${ }^{10}$ Banco da Amazônia (BASA) e Banco do Brasil.

${ }^{11}$ Esses fungos causam Podridão-das-raízes e Podridão-do-pé das plantas de pimenta-do-reino. Fonte:<<http://www.ceplac.gov.br/radar/pimentadoreino.htm>> acesso 11/03/2019.
} 
instalados no Estado do Pará, principalmente na região nordeste, a ramificarem o plantio por vários municípios, o que fez do Brasil, a partir do Pará, no contexto da década de 80, o maior produtor mundial (FILGUEIRAS, et. al., 2010).

Essa intensa produção decorria de um processo histórico de cultivo implementado no Pará, tanto que, a partir de 1970, na região Vale do Rio TambaíAçu, no entorno à Comunidade Quilombola Tambaí-Açu ${ }^{12}$, Mocajuba/PA, mais de 60 mil pés de pimenta-do-reino foram introduzidos pelos japoneses, com subsequente aumento da produção, conforme fala do quilombola $R$. N. C., e dados dos relatórios dos censos agrícolas $(1970,1980)$ produzidos e publicados pelo IBGE ${ }^{13}$ (Instituto Brasileiro de Geografia e Estatística), provocando a entrada das populações tradicionais como força de trabalho nessa ação do capital na região, atuando contra seus modos de produzir a existência:

[...] aqui perto, chegou a ser plantado na década de 70 (setenta), mais de 60 mil pés de pimenta. Muita gente daqui da comunidade trabalharam nestes pimentais. Vinha gente até de Cametá pra cá. Os japoneses tinham grandes armazéns e o povo dormia por aí mesmo. Famílias inteiras "saía" aí mesmo, até finalizar a colheita, era muita gente[...] (ENTREVISTA, $\left.3^{14}\right)$

Assim, conforme a fala do quilombola R. N. C. (ENTREVISTA, 3), inferimos que, a partir da década de 70 , ocorreram profundas mudanças nas relações de trabalho no território de Tambaí-Açu, com a entrada maciça de homens e mulheres nas atividades de cultivo da pimenta-do-reino, com alterações nos modos de vida das populações tradicionais, inclusive na materialidade dos saberes do trabalho aí presentes. Seduzidos ideologicamente pelo trabalho nos pimentais, com a perspectiva de remuneração em decorrência de colheita e cuidados no cultivo realizados, mas, na realidade, constituindo-se mão-de-obra barata, muitos trabalhadores e trabalhadoras assumiram o trabalho coisificado, repetitivo e estranhado do trato com a pimenta, tendo que viver aglutinados/as em grandes armazéns (galpões), famílias inteiras, como salienta $R$. N. C., em detrimento do trabalho em suas próprias produções

\footnotetext{
${ }^{12}$ Comunidade legalmente reconhecida pelo Estado como Comunidade de Quilombo em 2009, pelo ITERPA (Instituto de Terras do Pará).

${ }^{13}$ Conforme dados obtidos em: https://biblioteca.ibge.gov.br

${ }^{14}$ Fala coletada em conversa informal, durante o processo de observação na comunidade, de 2017 a 2019, registrada em anotações de campo.
} 
agrícolas, onde colaboração e congraçamento eram tônicas do fazer-se no/pelo trabalho. Na verdade,

Quando a pimenta-do-reino chega, ocorreu assim: o pessoal que trabalhava no sistema do mutirão passou a trabalhar pros patrões e largaram mais de trabalhar no mutirão, que se tinha pra trabalha só pra si, e começaram a trabalhar pro outro; e se ocupavam a trabalhar com o trabalho do outro; e se esqueceram de fazer o mutirão [...] (ENTREVISTA, 3).

Frente a essa realidade, entendemos que, considerando as mediações de segunda ordem do capital, "[...] que buscam assegurar o controle sociometabólico do capital", conforme Tiriba e Fischer (2015, p. 415), no processo de introdução e manutenção do monocultivo intensivo da pimenta-do-reino na comunidade estudada, o trabalhador tem sido explorado por meio do sistema de assalariamento voltado a pagar diárias aos trabalhadores, muito abaixo da força de trabalho empreendida, fazendo com que famílias inteiras e seus modos de vida subordinem-se à exigência de expansão do sistema do capital. Para Mészáros (2011):

\begin{abstract}
A constituição do sistema do capital é idêntica à emergência de sua segunda ordem de mediações. O capital em si não passa de um modo e um meio dinâmico de mediação reprodutiva, devorador e dominador, articulado como um conjunto historicamente específico de estruturas e suas práticas sociais institucionalmente incrustadas e protegidas. É um sistema claramente identificável de mediações que, na forma adequadamente desenvolvida, subordina rigorosamente todas as funções de reprodução social - das relações de gênero e família até a produção material e a criação das obras de arte - à exigência absoluta de sua própria expansão, ou seja: de sua própria expansão constante e de sua reprodução expandida como sistema de mediação sociometabólico. (MÉSZÁROS, 2011, p. 118)
\end{abstract}

Neste contexto, as trabalhadoras e os trabalhadores quilombolas experienciaram o trabalho nos pimentais e, diferente do trabalho da roça, em que unem forças para produzir, agindo em regime de colaboração e produzindo conforme suas necessidades, alguns passaram a trabalhar individualmente, por salários pagos de acordo com a produção, sempre baixos, o que exigia maior intensificação do trabalho, fazendo com que toda uma família atuasse horas e horas em prol do aumento da colheita, a fim de se obter um pouco mais de recursos. Nos pimentais, experienciaram o trabalho análogo à escravidão, de acordo com o entrevistado $R$. N. $C$.: "A maioria do nosso povo passou a trabalhar como escravo, porque deixaram os nossos afazeres e passaram a trabalhar com os patrões, nos negócios do dinheiro, né? Da pimenta-do-reino". 
Diante dessa situação, compreendemos que o processo histórico de formação das comunidades tradicionais quilombolas no Pará constituiu-se como resultado das travessias operadas pelo modo de produção capitalista, sempre com necessidade voraz de expansão, conforme Mello (2001). Tanto é que os povos negros foram arrancados de seus territórios na África para serem escravizados no Brasil, de modo a intensificar o processo de acumulação, concentração e centralização desse sistema, conforme destacam Reis e Gomes (2012, p. 09), para os quais, "[...] não obstante o uso intensivo da mão de obra cativa indígena foram os africanos e seus descendentes que constituíram a força de trabalho principal durante os mais de trezentos anos de escravidão". E era nessa perspectiva de maximização da lucratividade capitalista que também a força de trabalho nos pimentais era requerida.

Por outro lado, há de se considerar que as comunidades quilombolas, como a de Tambaí-Açu, constituídas no Estado do Pará a partir desse contexto históricopolítico-cultural de surgimento de quilombos vieram, ao longo dos tempos, caracterizando-se como formas de organização de resistência à exploração da vida, que coisifica homens e mulheres, como o observado em atividades produtivas da monocultura da pimenta-do-reino. Nos quilombos prevaleciam de territórios eivados, contraditoriamente, por outras sociabilidades de trabalho, em que a parceria, o trabalho coletivo, criador de vínculos de solidariedade, eram a tônica. Conforme palavras do entrevistado R.N.C.:

O mutirão não era só pra roça; ele tinha um sentido de amizade e muito [...]; e faziam essa amizade e não era só aqui dentro do quilombo, era nos lugares vizinhos como Igarapé Grande, Igarapé do Meio, Cantazal, Angelim; até no Acapuquara eles chegaram a fazer essa relação de mutirão; tinha gente de todo lado aí [...]; através do mutirão a ajuda [...] criou um vínculo de amizade; então não era só pra produção da roça; era também pra construir a amizade [...]

Ou seja, as comunidades quilombolas, como Tambaí-Açu, passaram a desenvolver espaços/tempos, a partir do trabalho, de produzir a vida associativamente, prevalecendo, com base em Tiriba e Fischer (2015), mediações de primeira ordem do capital, relacionadas à produção de subsistência de homens e mulheres, em que o trabalho visa à produção da vida, inclusive ao se vender ou trocar o excedente, pois o objetivo é suprir as necessidades vitais humanas. Para a autora, espaços/tempos do trabalho de produzir a vida associativamente: 
[...] são aqueles espaços/ tempos em que prevalecem as mediações de primeira ordem do capital, e que, coexistindo com o modo de produção capitalista, apresentam-se em diversas partes do mundo, entre elas nas comunidades onde habitam os povos originários latinoamericanos. (TIRIBA; FISCHER, 2015, p. 4).

Nesse contexto, negras e negros fugidos resistem e lutam até o presente tempo histórico, nas mais variadas formas de organização em comunidades tradicionais, conforme Reis e Gomes (2012), em prol de espaços-tempos do trabalho que produz vida e não exploração do outro, como a Comunidade Quilombola Tambaí-Açu e outras comunidades, no município de Mocajuba/Pará, como Itabatinga, Mangabeira, Porto Grande, Santo Antônio de Viseu, São Benedito de Viseu, Uxizal, Vizânia, São José de Icatu e Bracinho do Icatu. Entretanto, em todas elas são combatidas pelas ações do capital, a partir das mediações de segunda ordem, com a introdução do monocultivo intensivo da pimenta-do-reino, transformando 0 trabalho das comunidades tradicionais quilombolas em estranhamento, alienação.

Assim, observamos que as metamorfoses no[s] mundo[s] do trabalho ${ }^{15}$, operadas pelo modo de produção capitalista, transformam as relações sociais, fazendo com que, no contexto de Tambaí-Açu, a partir da introdução do monocultivo intensivo da pimenta-do-reino, o trabalho se constituísse estranhamento, como nos salienta a entrevistada C. N., para a qual o "[...] trabalho pro outro não produz a comunidade [...] o trabalho pro outro não te dá tempo pra mais nada, é só trabalhar, trabalhar [...] No trabalho pro outro, tu se escraviza a tua, sô", de maneira que a voracidade desse modo de produzir a vida vai adentrando vorazmente espaçostempos nunca imaginados, inclusive a subjetividade do ser humano, ou seja, as identidades, na tentativa de homogeneizar as heterogenias dos povos do campo.

Entretanto, mesmo com a tentativa de padronização do trabalho nas comunidades, com a instituição de uma intensificação e rotineirização da produção, via monocultivo da pimenta-do-reino, as comunidades resistiram, reconstituindo práticas produtivas e saberes relacionados ao trabalho nos mutirões, posto que os "[...] mutirões são organizados para se ajudarem" (E.N. C., ENTREVISTA 2) ao passo que no "[...] trabalho pro outro [...]" (ENTREVISTA 2) , nos pimentais, os sujeitos se individualizam, pois o ritmo do trabalho é pago pela produção, no cumprir de meta e

\footnotetext{
${ }^{15}$ Assumimos mundos do trabalho a partir de Hobsbawn (2000).
} 
horário: "[...] no [trabalho] do outro, tu entra sete horas, sete meia, sai meio dia, e de lá entra uma e meia, duas horas" (ENTREVISTA 2).

Assim, homens e mulheres da comunidade quilombola de Tambaí-Açu, a partir de suas materialidades, entre a[s] reproduç[ões] ampliad[as] do capital e a[s] reproduç[ões] ampliad[as] da vida (TIRIBA, 2018a), [re]criaram saberes sociais sobre o trabalho no mutirão, entendidos, conforme Rodrigues (2012, p. 57), como

[...] uma totalidade de conhecimentos resultantes da articulação presente-passado que permeia a existência dos seres humanos, considerando-se a dupla natureza da construção material dos homens: as condições de vida que encontram elaboradas antes do seu nascimento e aquelas que resultam de sua própria ação atual no mundo.

Sendo, de acordo com Fischer e Franzoi (2018, p. 209-210), mobilizados, modificados e/ou recriados em situação de trabalho, os saberes situam-se "[...] no polo da experiência de trabalho [...], num entendimento da experiência como 'saberes que podem se acumular no tempo de encontro com situações variáveis, históricas' (SCHWARTZ, 2010, p. 38)". E esses saberes se contrapõem à ordem capitalista em comunidades quilombolas, a exemplo do trabalho colaborativo, não assalariado, organizado através de mutirões. Para o quilombola R.M. G. N.:

Em todos os aspectos do trabalho que vejo, o mutirão de todas as formas foi quem contribuiu muito pra que a gente pudesse ter uma comunidade formada e hoje reconhecida, identificada, como comunidade quilombola. Uma comunidade que é de um povo que tem uma história [...] (ENTREVISTA, 1).

Percebe-se, assim, que os mutirões em Tambaí-Açu se configuram como outra forma de produzir a vida, para além da rotina e subjetividade de tempos-espaços fabris, com seus tempos de relógio e produção, como nos diria Thompson (1998, p. 268), para quem o "tempo do relógio" sobrepujou o "tempo da natureza", dos costumes e da vida em comunidade. Assim, os povos quilombolas se contrapõem à ordem capitalista ao se [re]criarem, através de mutirões, tempos-espaços de colaboração, congraçamento, festividade, amizades, e que não são apenas, no dizer do quilombola R. S. N.(ENTREVISTA, 4), "[...] para produzir a roça, mas para produzir amizade [...]", ou seja, humanização como tipo de experiência que, conforme Thompson (1998), também produz sentimento, valores, consciência. Por isso, o também chamado, segundo Pinto (2001), cunvidado, muxirum, putirum, para o quilombola J. C. N. (ENTREVISTA, 5) é 
[...] o mesmo mutirão, a gente fala convidado, porque a gente saía convidando, mas é o mesmo mutirão. Era a forma de reunir o povo pra trabalhar e olha, quando havia, assim, um grande convidado, quando era grande o convidado, é quando falo que era um roçado grande. A gente marcava, por exemplo, terça feira, era o meu convidado e aí todo mundo chegava, já na segunda-feira à tarde. la todo mundo pra lá, já pra tá lá cedo na terça feira, e aí acontecia. Surgia o banguê né? $\mathrm{E}$ o samba-de-cacete também. $\mathrm{E}$ aí a gente que ia com o banguê, levava o velho Toleco [in memoriam], ele era o cara, mesmo deficiente, ele tocava cuíca sabe? Ele era o compositor, ele só olhava ali e enversava na hora mesmo. Quando a gente tava tocando, ele tava ouvindo e inventava os versos na hora. Ele era do Juaba, mas casou com uma mulher daqui. [...] Ele tocava muito, ele inventou muita das músicas que nós canta. Muitas dessas músicas ele que inventava. $\mathrm{E}$ foi ele que versou muito disso que nós canta até hoje, que ficou na cabeça, e a gente lembra até agora. Muita coisa a gente também inventou, mas ele também contribuiu muito. Ele era muito bom de versar e, aí a gente tocava a noite inteira, bebendo cachaça, era comendo. E quando era no outro dia de manhã cinco horas o pessoá já tava de pé pra sair pra roça.

Nessa perspectiva, a partir do mutirão, o trabalho em Tambaí-Açu assumia outra conotação, diferente do exercido nos pimentais, permitindo a humanização de homens e mulheres, posto que a vida era regulada pelo companheirismo, no sentido etimológico latino de cum panis, de quem divide o pão e o trabalho que o produziu. Assim, o trabalho no encontro do mutirão quilombola tem o almoço, a janta, o chocolate com tapioca, as brincadeiras de ganzá ${ }^{16}$, as músicas do banguê ${ }^{17}$ e samba da cacete $^{18}$, o licor de murici e jenipapo, como instrumentos de trabalho. O mutirão quilombola tem o ritmo da animação dos trabalhadores. No mutirão quilombola, há

\footnotetext{
${ }^{16}$ Palavra de origem africana; é atribuída ao instrumento musical chocalho em forma de cilindro, com grãos ou pedras soltas dentro (Fonte: Dicionário, Unesp, 2011). Para os quilombolas do Tambaí-Açu, trata-se de brincadeira em formato de disputa entre dois músicos na composição de pequenos versos sobre assuntos do cotidiano. (Fonte: Anotações de campo, 2018)

17"O banguê é uma espécie de cantoria acompanhada de dança; é formado por um grupo de pessoas, que cantam em duas vozes, improvisando os versos musicais. Semelhante ao samba de cacete, possui letras que traduzem algum fato pessoal, popular ou regional. Episódios vividos que, musicados, passam de uma geração a outra. Os instrumentos mais comuns que acompanham as melodias do banguê são o roufo, a bandurra, a caixa, o violão, o reco-reco, o bumbo e o pandeiro. É uma dança rápida, saltadinha. Os dançarinos ou casais saem para roda (sala), a fim de dançar de rosto bem "coladinho" enquanto os bustos e quadris têm que se manter afastados (PINTO, 2001, p. 340).

${ }^{18}$ É uma espécie de batucada com participação de todos os presentes naquele momento; vem da improvisação, onde as músicas surgem livremente no momento ou, então, cantam-se as já tradicionais, passadas de uma geração para outra. Recebe o nome de samba de cacete porque os únicos instrumentos musicais são dois tambores, ou tambouros, como também é comumente denominado na região, de aproximadamente um metro e meio de comprimento, feitos pelos próprios habitantes das povoações negras rurais a partir de troncos ocos de árvores resistentes, como jareua, acapu, maçaranduba e cupiúba, os quais são ritualisticamente escavados no interior, tendo em uma das extremidades um pedaço de couro amarrado com cipó ou corda de curuanã, além de quatro cacetinhos de madeira (PINTO, 2013, p. 32).
} 
espaço para o lazer, que nos pimentais é suprimido pelo ritmo do relógio do empregador (THOMPSON, 1998). Nos pimentais vende-se o tempo-força do trabalho, nos mutirões doa-se, compartilha.

Entretanto, as transformações no[s] mundo[s] do trabalho, a partir da década de 1970 no Estado do Pará, mudaram a dinâmica dos mutirões, em termos de entrelaçamento com o batuque dos tambores, por meio do samba de cacete e do banguê, os quais passaram a ser realizados por grupos culturais, como "Quilombauê", com apresentações em dias comemorativos, como aniversários, dentre outros eventos. Entretanto, embora atravessados pelas necessidades de segunda ordem do capitalismo, através de monocultivos intensivos, a exemplo da pimenta-do-reino, as comunidades quilombolas do nordeste paraense têm dialeticamente [re]criado o mutirão no seu fazer-se, seguindo outras necessidades, como a de contribuir para uma identidade do ser social quilombola, favorecendo a demarcação de seus territórios de produção da vida, em comunidade.

Além disso, na atualidade, os mutirões em Tambaí-Açu continuam se configurando como trabalho que se opõe ao trabalho nos pimentais, pois é colaborativo, festivo, criativo, definindo a comunidade, enquanto identidade e organização quilombola. Conforme palavras de M. L. R. P, em que o trabalho no/pelo mutirão se constitui também educativo:

Os mutirões são uma necessidade, hoje, para comunidade, assim como no passado, pois, eu como professora, sempre oriento meus alunos sobre o que é o mutirão, o que significa para nós. [...] a gente conversa em sala de aula sobre o mutirão, [...] orienta [...] e, na prática, a gente faz o mutirão com as crianças duas vezes aqui na comunidade $[\ldots]$

Dessa forma, observa-se a organização do trabalho nos mutirões para além da ação espontânea movida pela tradição, mas como ação conotativa de formação política, pois mantém, embora as investidas do capital, a comunidade unida na luta pela sobrevivência e pela garantia de seus direitos enquanto território de quilombo. $A$ formação da consciência, a partir do trabalho nos mutirões, com as mediações culturais, sociais, econômicas, políticas e produtivas nele presentes, tem favorecido a (re)afirmação do ser social quilombola permeado de cultura popular, a partir também da constituição de um espaço-tempo de formação no interior da Associação da Comunidade Remanescente de Quilombo Tambaí-Açu (ACREQTA), fundada em 2001. Esta Associação tem contribuído no despertar das lideranças da Comunidade 
Quilombola do Tambaí-Açu para o autorreconhecimento e para (re)afirmação da identidade quilombola, corroborando com a [re]construção de suas identidades enquanto comunidade tradicional, na contradição entre dois modos de vida: um voltado às reproduções ampliadas da vida e outro para as reproduções ampliadas do capital, além de integrar, de forma definitiva, a Comunidade ao Movimento Negro Quilombola e à construção de uma agenda de lutas por políticas públicas, que levaram, por exemplo, à Titulação do Território Quilombola de Tambaí-Açu, dentre outras conquistas.

Assim, [re]criam, até o tempo histórico presente, saberes do trabalho, a partir dos mutirões, unindo forças, vivendo o festivo, o colaborativo, o criativo e humanizante. Este tipo de trabalho é a base para a formação da identidade econômico-cultural que mantém a comunidade e destoa da desumanizante identidade do capital, pautada no consumo e na exploração do trabalho. No dizer de Mészáros (2011, p. 185), trata-se do "[...] domínio absoluto sobre todos os seres humanos, mesmo na forma mais desumana, quando estes deixam de se adaptar a seus interesses e a seu impulso para a acumulação".

\section{Identidades de comunidades quilombolas: entre a negação e aderência ao modo de produção capitalista}

Com relação aos processos de [re]construção das identidades do ser social quilombola, entendemos que suas bases estão nas materialidades produtivas da existência, tanto objetivas como subjetivas, mediadas pelos processos de resistências que se engendram na contradição trabalho-capital, tal qual o disposto por Dubar (2005), para o qual a [re]construção das identidades é um processo de formação mediado pelas relações constitutivas na produção da vida real, que perpassam tanto pela ordem econômica como cultural (DUBAR, 2005).

Neste sentido, destaca-se, entre os diversos saberes sociais, a experiência do mutirão como principal fundamento do pensar-resistir quilombola sobre a realidade, possibilitando-Ihes [re]criar processos de mediação à tentativa de homogeneização produtiva cultural, operada pelo modo de produção capitalista através da introdução de monocultivos intensivos nos espaços rurais amazônicos, a exemplo da pimentado-reino no Estado do Pará. 
Assim, entende-se que neste conflito, entre resistir e aderir ao modo de produção capitalista, o povo quilombola [re]constrói, conforme Dubar (2005), a consciência de si-outro, enquanto identidade de ser social negro de uma comunidade quilombola, decorrente de processos de socialização mediados pelo trabalho. De acordo com Dubar (2005, p. 136), identidade "[...] é o resultado a um só tempo estável e provisório, individual e coletivo, subjetivo e objetivo, biográfico e estrutural, dos diversos processos de socialização que, conjuntamente, constroem os indivíduos e definem as instituições".

E são esses processos de socialização no trabalho que thes foi possibilitando a base da formação da identidade econômico-cultural, que Ihes permite a organização política e produtiva. Conforme Tiriba e Fischer (2015, p. 407), é "[...] na relação com o outro ser humano, com outros grupos e classes sociais, que produzimos saberes sobre possíveis maneiras de (ser)estar no mundo", de tal maneira que o sujeito de saber se apropria do saber, por meio de uma construção coletiva, consubstanciando experiências vividas, percebidas e modificadas (THOMPSON, 1987). Essas relações foram possibilitando aos quilombolas de Tambaí-Açu um saber social experienciado sobre o estar no mundo em função de um trabalho para o outro e um trabalho para o coletivo, para a vida em comunidade. Conforme palavras da entrevistada E. N. C., para quem o trabalho nos mutirões é:

[...] em conjunto, e a gente se sentia bem, por que não tinha trabaio que a gente não desse conta, como de capina. A gente trabaiava em conjunto. Nós se reunia muitos, mulherada, pra trabalhar e trabaiava nos trabaio de cada pessoa, de cada família né? E trabaiava também no trabaio da comunidade. E a gente ia aprendendo. Todo mundo se serviam ali, trabaiando, conversando, e a gente conseguia. Com o trabalho pro outro, mudou a gente e passamo a trabaiá já num outro ritmo, servindo o outro. [...] No mutirão, um ajudava o outro e depois a gente fazia, assim o convidado. E aí a gente tinha o direito de dá a comida, de dá a merenda, lá. Os convidado era muito animado. A gente fazia as brincadeiras, mas eram as brincadeiras mais animadas, como esse que a gente tem até hoje o banguê. E eles faziam o sambade-cacete.

Compreende-se, desta maneira, o cruzamento de dois processos relacionais, ou seja, em que o sujeito é analisado pelo outro dentro dos sistemas de ação nos quais os sujeitos estão inseridos, e biográficos, que tratam sobre a história, habilidades e projetos do sujeito, aqui analisado como trabalhador. Assim a "identidade para si" e "identidade para o outro" são assimétricas, pois a primeira é 
correlatada à segunda, de maneira que a identidade do ser social negro, a partir dos mutirões, resulta de uma perspectiva do outro, aqui entendido como o modo de produzir o trabalho nos pimentais, como o espaço-tempo que é estranhado, posto que "Com o trabalho pro outro, mudou a gente e passamo a trabaiá já num outro ritmo, servindo o outro", conforme E. N. C. Mas que, dialeticamente, por oposição, permite a construção de uma identidade para si, a partir dos mutirões, como o lugar do prazer, ao lado do labor, já que, de acordo ainda com E. N. C., "No mutirão, um ajudava o outro e depois a gente fazia, assim o convidado. E aí a gente tinha o direito de dá a comida, de dá a merenda, lá. Os convidado era muito animado".

Assim, a [re]construção das identidade[s] no Quilombo Tambaí-Açu tem se dado no perceber-se explorado no "trabalho pro outro", como nos disse $T$. C.(Entrevista, 6), confirmado por R. S. N. (Entrevista 4) como trabalho "[...] que não dá resultado [...]", pois causa a individualização pelo salário, e não paga a força do trabalho despendido pelo/a trabalhador/a.

Nessa luta de contrários, o trabalhador resiste, retorna ao trabalho que herdou de seus antepassados e reconstrói sua própria identidade, configurada no dizer dos sujeitos trabalhadores, na prática de trabalho do mutirão, como o lugar identidade e saber colaborativo, de aprendizagem coletiva, uma vez que nos mutirões, de acordo com E. N. C., "A gente trabaiava em conjunto. Nós se reunia muitos, mulherada, pra trabalhar e trabaiava nos trabaio de cada pessoa, de cada família né? E trabaiava também no trabaio da comunidade. $\mathrm{E}$ a gente ia aprendendo. Todo mundo se serviam ali, trabaiando, conversando, e a gente conseguia", numa evidência de que, de acordo com Dubar (2005, p. 135), a "[...] identidade nunca é dada, ela é sempre construída e deverá ser (re)construída, em uma incerteza maior e menor e mais ou menos duradoura". A identidade, como parte da formação da classe econômico-cultural, que vive do trabalho ${ }^{19}$, se (re)constrói ao perceber-se explorado, inter-relacionado ao ato de construção de alternativas, isto é, o saber do trabalho - mutirão.

Diante dessa situação, entendemos que, historicamente, a tentativa de homogeneizar as heterogenias de povos tradicionais quilombolas, por parte do modo de produção capitalista, tem-se materializado em um campo de contradição de saberes sociais entre capital e trabalho. Essa luta produz processos de resistência

\footnotetext{
${ }^{19}$ Para E. P. Thompson (1987, p. 13) "a classe é uma formação tanto cultural como econômica". De maneira invertida, utilizamos a expressão "classe econômica-cultural", que ainda merece aprofundamento teórico e empírico.
} 
que [re]constroem saberes como o mutirão e com isso [re]constroem identidades quilombolas. Deste modo, estes processos dão às resistências um caráter contraditório, ou seja, uma perspectiva de negação-aderência ao sistema capital que Thompson (1998, p. 20) nomeou como deferente-rebelde, pois os povos quilombolas de uma forma ou de outra também foram, em algum momento e/ou razão, "seduzidos" ideologicamente por esta lógica, Como nos revelou a quilombola $E$. N. C., recrutada ao trabalho de colheita nos pimentais na década de 1980:

Quando comecei a trabaiá, eu cheguei a trabaiá, aí nos pimentar, por duzentos cruzeiros por dia. Duzentos que hoje é vinte centavo. Eu trabaiava... nós saía daqui quatro horas da manhã. Eu saía de casa, eu saía junto com os pessoá do Copa... [in memoriam], a mulherada... e a gente ia embora pra lá. A gente ia andando por tudo aí, e ia saí lá onde hoje é a fazenda do Amilcar, lá por onde vai pela estrada. Pra aí nós ia trabaiá a diária e hoje se chama vinte centavo, naquele tempo era cruzeiro. [...] Com a pimenta-do-reino, eu achei que mudou até assim, que é o trabalho pro outro [...], no serviço da gente, se a gente quiser entrar oito horas a gente entra, se a gente quiser sair nove a gente sai, e é assim que é, e no do outro não, você vai entrar sete horas/sete meia, sai meio-dia e de lá entra uma e meia/duas horas...(ENTREVISTA, 2)

O dizer da quilombola E. N. C. (ENTREVISTA,2) apresenta a forma como as transformações no[s] mundo[s] do trabalho foram operadas, no contexto da Comunidade Quilombola Tambaí-Açu, Mocajuba/PA, pela introdução do monocultivo intensivo da pimenta-do-reino e de como estas transformações tentaram imprimir nestes quilombolas uma identidade de aderência ao modo de produção capitalista.

Entretanto, as tentativas do racionalismo do capital de homogeneizar as heterogenias não obtiveram êxito em sua totalidade, pois, de acordo com Vendramini e Tiriba (2014, p. 55), mesmo: "[...]Imersas no sistema capitalista, nos dias atuais, outras culturas do trabalho se manifestam nas experiências marcadas pela resistência econômica e cultural à produção capitalista". A partir da experiência nos pimentais, a trabalhadora e o trabalhador perceberam, assim como no dizer da quilombola E.N. C. (ENTREVISTA,2), que o "[...] trabalho pro outro [...]"é diferente do modo produzir a vida tradicionalmente na comunidade, assim param de trabalhar "pro outro" e, como nos disse a mesma, "[...] voltemos de novo ao trabalho que nós era acostumado". Nessa perspectiva, configura-se uma tomada de decisão voltada para um modo de existência pautado no bem viver, com base em pressupostos de economias associativas em que trabalhos coletivos e humanizantes, definidos em termos de 
solidariedade-reciprocidade, passam a ordenar a vidas das pessoas, em oposição à lógica predadora capitalista, conforme Pimentel (2014).

Desta forma, ao nos revelar a quilombola T. C. (ENTREVISTA, 6): "[...] nunca trabalhei em pimentá [...]", pois construiu a consciência traduzida em seu dizer que “[...] o trabalho pro outro não produz a comunidade [...]", entende-se que os quilombolas [re]constroem, na formação da consciência (THOMPSON, 1998), os mutirões e o fazer-se quilombola, uma vez que, nos pimentais, as trabalhadoras e trabalhadores quilombolas vivenciaram o trabalho diferente do trabalho da autogestão em suas roças, vivendo, isto sim, o trabalho no molde fabril, rotineiro, enfadonho, em que não há espaço para o lazer, a festividade, a cultura dos mutirões, do cuidar do outro, do bem viver, portanto, mas havendo, sim, o trabalho mecanizado e desumanizado do capital. Entretanto, mesmo seduzidos ideologicamente pelo sistema de assalariamento, operado nos pimentais, ao trabalharem, principalmente nos períodos da colheita, como forma de complementação de renda, a experiência do trabalho nos pimentais não foi suficiente para destruir o sentido do trabalho no mutirão quilombola. Mesmo tendo vivenciado o trabalho, no dizer dos sujeitos "pro outro", isto é, nos pimentais, o saber social do trabalho mutirão, embora modificado, tem-se (re)criado, como resistência econômico-cultural ao sistema capital, personificado no monocultivo intensivo da pimenta-do-reino.

Assim, em meio à precarização das condições de trabalho, os quilombolas do Tambaí-Açu, Mocajuba/PA, resistiram ao capital, [re]construindo processos de organização e alternativas, ao que chamam as quilombolas E. N. C. (ENTREVISTA, 2) e T. C. (ENTREVISTA, 6) de "trabalho pro outro", ou seja, ao trabalho nos pimentais, configurando uma identidade de resistência ${ }^{20}$, através dos saberes do trabalho, colaborativo, festivo, criativo que compõem o mutirão quilombola.

Neste sentido, observa-se a organização do trabalho nos mutirões da Comunidade Quilombola Tambaí-Açu como base do processo da formação [constante] da classe, conforme Thompson (1998), econômico-cultural, que vive do trabalho (ANTUNES, 2009) permeado de cultura popular (THOMPSON, 1998).

Ao mesmo tempo, para além do monocultivo da pimenta-do-reino, constamos ainda que o capital, embora tenha fixado seus empreendimentos através de grandes

${ }^{20}$ Conforme CALTELLS, Manoel. O Poder da Identidade. Tradução Klauss Brandini Gerhardt. 2 ed. São Paulo: Paz e Terra, 2000. 
pimentais no município de Mocajuba, desde 1970, em meio às metamorfoses dos dias atuais, continua introduzindo outros monocultivos na região nordeste paraense a exemplos do Dendê21, Paricá ${ }^{22}$ e mais recente a produção em larga escala do monocultivo intensivo (irrigado) do Açaí ${ }^{23}$, procurando, com isso, intensificar ainda mais o processo de homogeneização das identidades dos povos do campo ${ }^{24}$, como os quilombolas. No entanto, mesmo tentando aniquilar as heterogenias, o capitalismo não tem tido êxito, pois o mundo humano, como já vimos, é um constante vir a ser (THOMPSON, 1998).

Nesse movimento, os povos tradicionais quilombolas, como da Comunidade Tambaí-Açu, têm sido resistentes à identidade individual, parcelada, empreendedora, previsível e desumanizante imposta pelo modo de produção capitalista e, neste mesmo mundo, objetivo, se [re]criam, se [re]constroem através de alternativas e/ou outras objetividades, a exemplo do trabalho colaborativo, criativo, festivo, humanizante materializado nos mutirões quilombolas até o tempo histórico presente.

Ressalta-se que, embora tenham os quilombolas avançado em relação à organização e luta por direitos, tendo acesso, inclusive, a algumas políticas públicas que Ihes deram "certa" visibilidade enquanto sujeitos de direito, ainda há muito caminho a ser percorrido, dado o processo histórico excludente operado em tornar invisíveis a negras e negros deste país.

Entretanto, torna-se crucial registrar que a [re]construção das identidades quilombolas na perspectiva da formação de classe pensada por Thompson (1998),

\footnotetext{
${ }^{21} \mathrm{O}$ dendezeiro (Elaeis guinensis Jacq) é uma palmeira existente nas regiões tropicais e originária da África. A cultura foi introduzida no continente americano a partir do século $\mathrm{XV}$, e produz o óleo conhecido no Brasil como azeite de dendê, e no mundo, como Palm Oil, sendo utilizado para diversos fins na indústria de alimentos, cosméticos, higiene e limpeza, agroenergia e biocombustíveis. Fonte: $<<$ http://www.sedap.pa.gov.br, acesso em 12/04/2019>>

${ }^{22} \mathrm{~A}$ espécie Shizolobium amazonicum (paricá), por apresentar rápido crescimento, fuste reto e madeira com elevada cotação no mercado interno e externo, vem sendo bastante cultivada pelas empresas madeireiras da região norte e nordeste do país, principalmente nos Estados do Pará e Maranhão. Fonte: <<http://www.ciflorestas.com.br, acesso em 12/04/2019>>

${ }^{23}$ Alimento típico amazônico (Euterpe oleracea Mart.), atualmente produzido através de monocultivos, em larga escala, para suprir as necessidades do mercado e indústria de alimentos tais como: suco, palmito, dentre outros, tanto a nível nacional como mundial.(Anotações de campo, 2018)

${ }^{24}$ Nessa dimensão mais teórico-conceitual, os termos "povos e comunidades tradicionais" buscam uma caracterização sócio-antropológica de diversos grupos. Estão incluídos nessa categoria povos indígenas, quilombolas, populações agroextrativistas (seringueiros, castanheiros, quebradeiras de coco de babaçu), grupos vinculados aos rios ou aomar (ribeirinhos, pescadores artesanais, caiçaras, varjeiros, jangadeiros, marisqueiros), grupos associados a ecossistemas específicos (pantaneiros, caatingueiros, vazanteiros, geraizeiros, chapadeiros) e grupos associados à agricultura ou à pecuária (faxinais, sertanejos, caipiras, sitiantescampeiros, fundo de pasto, vaqueiros). (CALDART, et. al, 2012, p. 597,598$)$
} 
além de ser um constante processo, precisa ser analisada com cuidado (TIRIBA, 2018a), para não cair nas armadilhas das generalizações eurocêntricas.

\section{Considerações finais}

As formas de resistência ao trabalho no modo de produção capitalista na Comunidade Quilombola Tambaí-Açu têm se dado nas lutas e mediações dos saberes do trabalho, a exemplo do ato festivo e colaborativo dos mutirões, contrários às transformações operadas pelas necessidades do capital, ao implantarem monocultivos intensivos como a pimenta-do-reino, em favor da produção em larga escala e a suprir as necessidades do mercado mundial.

Tal movimento tem possibilitado [re]criar a identidade quilombola como formação da classe econômico-cultural, que vive do trabalho, a partir dos mutirões e do trabalho agrícola, como um todo, favorecendo, na Comunidade Quilombola Tambaí-Açu, uma [re]construção de identidades, no sentindo de fortalecer as lutas do ser trabalhador-quilombola.

Embora o escopo deste artigo não permita aprofundamento, acreditamos que o mutirão se constitui como prática de Bem Viver, resistindo à lógica do capital, pois, ao cuidar do outro, constrói o bem a si mesmo. Para Acosta (2016), o Bem Viver implica que para eu estar bem, o outro precisa estar bem também.

Além disso, a pesquisa revelou, dentre outros achados, que os quilombolas e quilombolas, diante da lógica do capital, (re)construíram o saber de uma produção comunitária que, embora não tenha socializado diretamente o que produziram, favoreceu saberes de uma economia voltada para a subsistência, para a organização e para a comunicação de todos. Economia para subsistência, diferente do que se opera na economia para o capital, enquanto intensificação da produção para o acúmulo de propriedade, lucro, consumo, dinheiro e riqueza. Produção capitalista configurada em monocultivos, agronegócio, para a larga escala, objetivada a suprir às necessidades do mercado, em detrimento do ser humano e do seu bem viver.

O Bem Viver, conforme Acosta (2016, p. 84), "[...] aponta a uma ética da suficiência para toda a comunidade e não somente para o indivíduo. Sua preocupação central, portanto, não é acumular para então viver melhor", como ousa imprimir o capitalismo, ao tentar inviabilizar a sobrevivência e (re)construção das comunidades, a exemplo do que se tentou realizar na Comunidade Quilombola Tambaí-Açu, desde 
sempre, entre outras formas, ao recrutar os quilombolas ao trabalho assalariado no agronegócio.

Assim, como perspectiva de encaminhamentos a outras questões e outros estudos, propomos continuar pensando de que forma estes mutirões podem ser [re]configurados como elementos apresentados por Acosta (2016) como Bem Viver. Como se [re]constroem as identidades entre os jovens quilombolas no atual contexto do capitalismo? De que forma a universidade pode ir além de seus muros, aprender e contribuir com experiências humanizantes, materializadas em comunidades tradicionais?

Por fim, enfatizamos que, como não há neutralidade na ciência, o compromisso deve ser com a verdade, de ir além das aparências, compreender radicalmente o processo histórico que constitui a ação humana, pela experiência da vida material (KOSIK, 2002). Compromisso necessário, dado o tempo-espaço presente em que experenciamos em nosso país, povos tanto do campo como da cidade vivenciando a supressão de direitos conquistados com luta.

\section{Referências}

ACOSTA, Alberto. O Bem Viver: Uma oportunidade para imaginar outros mundos. Tradução: Tadeu Breda. São Paulo: Autonomia Literária; Elefante, 2016.

ANTUNES. Ricardo. Os sentidos do trabalho: ensaio sobre a afirmação e a negação do trabalho. [2.ed., 10.reimpr. rev. e ampl.]. - São Paulo, SP : Boitempo, 2009.

ARAÚJO, Ronaldo. O marxismo e a pesquisa qualitativa como referências para investigação sobre educação profissional. In: Relatório de Pesquisa do Projeto de Pesquisa "Práticas Formativas em Educação Profissional: em busca de uma didática de educação profissional”, financiada pelo CNPq. 2007. Disponível em: www.ufpa.br/ce/gepte, acesso em: 18.05.2017.

BORBA, Francisco S. Dicionário UNESP do Português Contemporâneo. São Paulo: Piá, 2011.

BARDIN, Laurence. Análise de conteúdo. Lisboa: Edições 70, 1977.

CALDART, Roseli Salete. et al. (Org.). Dicionário da Educação do Campo. Rio de Janeiro/São Paulo: EPSJV/ Expressão Popular, 2012.

DUBAR, Claude. A socialização: construção das identidades sociais e profissionais. São Paulo: Martins Fontes, 2005. 
FISCHER, Maria C.; FRANZOI, Naira Lisboa. Experiência e Saberes do Trabalho: Jogo de luz e sombras. In: MAGALHÃES, Lívia Diana R.; TIRIBA, Lia. Experiência: o termo ausente? Sobre história, memória, trabalho e educação. Uberlândia, MG: Navegando, 2018.

FILGUEIRAS, Gisalda Carvalho et. al. Conjuntura do mercado da pimenta-do-reino no Brasil e no mundo. ICSA/UFPA. Belém, 2010.

FLOHRSCHÜTZ, Gerhard Hubert Hermann e Alfredo Kingo Oyama Homma (org.). 0 processo de desenvolvimento e nível tecnológico de culturas perenes: 0 caso da pimenta-do-reino no nordeste paraense. EMBRAPA.CPATU. Documentos, 23. Belém - Pará, 1983.

FUNES, Eurípedes A. Nasci nas matas, nunca tive senhor. História e memória dos mocambos do baixo Amazonas. In: REIS, João; GOMES, Flávio dos Santos (org.). Liberdade por um fio: história dos quilombos no Brasil. São Paulo: Claro Enigma, 2012.

GOMES, Flávio dos Santos. Ainda sobre os quilombos: repensando a construção de símbolos de identidade étnica no Brasil. In: REIS, E.; ALMEIDA, M. H. T. de; FRY, P. (org.). Política e Cultura. Visões do passado e perspectivas contemporâneas. São Paulo: ANPOCS/Hucitec, 1996. p. 197-221.

. Nos labirintos dos rios, furos e igarapés: camponeses negros, memória e pósemancipação na Amazônia, c. XIX e XX. História Unisinos, set./dez. 2006. Disponívelem:http://www.scielo.br/scielo.php?script=sci_nlinks\&ref=000124\&pid=S00 02. Acesso em: 1 jul. 2018.

Mocambos e Quilombos - Uma história do campesinato negro no Brasil. São Paulo: Companhia das Letras, 2015.

HOBSBAWN, Eric J. Mundos do trabalho. Tradução: Waldea Barcellos e Sandra Bedran. 4aㅡ ed. Rio de Janeiro. Paz e Terra. 2000.

KOSIK, Karel. Dialética do concreto. Rio de Janeiro: Paz e Terra, 2002.

MARX. Karl. O Capital I. Tradução: Rubens Enderle. Editora Boitempo. São Paulo. 2013.

. Contribuição à crítica da economia política. Tradução: Florestan Fernandes. $-2^{\mathrm{a}}$ ed. Expressão Popular. São Paulo. 2008.

MELLO. Alex Fiuza de. Modo de produção Mundial e Processo Civilizatório: Os horizontes históricos do capitalismo em Marx. Editora Paka-Tatu. Belém. 2001

MESZÁROS. Stiván. Para além do Capital: rumo a uma teoria da transição. Tradução Paulo Cezar Castanheira, Sérgio Lessa. - 1.ed. revista. - São Paulo: Boitempo, 2011. 
NOSELLA, Paolo. Trabalho e educação: território e globalização. In: Anais do VIII Colóquio de Pesquisa em Instituições Escolares: pedagogias alternativas. PPGE da UNINOVE /SP, de 09 a 11 de novembro de 2011. Disponível em: << http://forumeja.org.br/sites/forumeja.org.br/files/5. Trabalho Educacao e Territorio NOSELLA Paolo 2011.pdf >>.

PINTO, Benedita Celeste de Moraes. Escravidão, fuga e a memória de quilombos na região do Tocantins. São Paulo: PUC-SP, 2001.

. Nas Veredas da sobrevivência: memória, gênero e símbolos de poder feminino em povoados amazônicos. Belém: Paka-Tatu, 2004.

Memória, oralidade, danças, cantorias e rituais em um povoado amazônico. Cametá, PA: BCMP, 2007.

Samba-de-cacete: ecos de tambores africanos na Amazônia Tocantina. In: Tambores e Batuques: Sonora Brasil/Circuito 2013-2014. Rio de Janeiro: Sesc, Departamento Nacional, 2013. p. 28-37.

PIMENTEL, Boris Marañón. Crisis global y descolonialidad del poder: la emergência de una racionalidad liberadora y solidaria. In: PIMENTEL, Boris Marañón (Org.). Buen vivir y descolonialidad: crítica al desarrollo y la racionalidad instrumentales. Primera edición. - México: UNAM, Instituto de Investigaciones Económicas, 2014.

REIS, J. J.; GOMES, Flávio S. (org.). Liberdade por um fio - História dos Quilombos no Brasil. São Paulo: Claro Enigma, 2012.

RODRIGUES, Doriedson do S. Saberes sociais e luta de classes: um estudo a partir da colônia de pescadores artesanais Z-16 Cametá/ Pará, 2012. Tese (Doutorado em Educação) - Programa de Pós-Graduação em Educação, Instituto de Ciências da Educação, Universidade Federal do Pará, Belém, 2012.

SALLES, Vicente. O negro no Pará: sob o regime da escravidão. 2. ed. Belém: Secretaria de Estado da Cultura; Fundação Cultural do Pará "Tancredo Neves", 1988.

SCHWARTZ, Yves. A experiência é formadora? Revista Educação e Realidade, v. 35, n. 1, p. 35-48, jan./abr. 2010.

TIRIBA, Lia. Fios invisíveis do (s) mundo (s) do trabalho: A experiência à lupa. In: MAGALHÃES, Livia Diana R. e Lia Tiriba, (org). Experiência: o termo ausente? Sobre história, memória, trabalho e educação. Navegando. Uberlândia/Minas Gerais. 2018a.

Reprodução ampliada da vida: o que ela não é, parece ser e pode vir a ser. Otra Economía, vol. 11, n. 20, p. 54-87, julio-diciembre. 2018b.

TIRIBA, Lia; FISCHER, Maria Clara Bueno. Espaços/tempos milenares dos povos e comunidades tradicionais: notas de pesquisa sobre economia, cultura e produção de saberes. R. Educ. Públ., Cuiabá, v. 24, n. 56, p. 405-428, mai./ago. 2015. 
TRIVIÑOS, Augusto N. S. Introdução as pesquisas em ciências sociais: A pesquisa qualitativa em Educação. São Paulo: Atlas, 1987.

THOMPSON. E. P. A formação da classe operária inglesa v. I, II, III. $4^{\mathrm{a}}$ ed. Paz e Terra. São Paulo. 1987.

Costumes em Comum. Estudos sobre a cultura popular tradicional. Trad.: Rosaura Eichemberg. Companhia das Letras. São Paulo. 1998.

Modos de dominação e revoluções na Inglaterra. In: NEGRO, Antonio Luigi; SILVA, Sergio. (Org.). As peculiaridades dos ingleses e outros artigos. Campinas: Editora da UNICAMP, 2001. p. 269-281.

VENDRAMINI, Célia Regina, TIRIBA, Lia. Classe, cultura, e experiência, na Obra de E. P. Thompson: Contribuições a pesquisa em educação. Revista HISTEDBR Online, Campinas, № 55, p. 54-72, mar 2014 - ISSN: 1676-2584. 